\title{
Khat Use and Trait Anger: Effects on Affect Regulation during an Acute Stressful Challenge
}

\author{
Stephan Bongard ${ }^{\mathrm{a}} \quad$ Mustafa al'Absi $^{\mathrm{b}} \quad$ Najat Sayem Khalil ${ }^{\mathrm{c}} \quad$ Molham Al Haboric \\ ${ }^{a}$ Goethe University, Frankfurt am Main, Germany; ${ }^{b}$ University of Minnesota School of Medicine, Duluth, Minn., USA; \\ 'Sana'a University, Sana'a, Yemen
}

Key Words

Khat $\cdot$ Emotion regulation $\cdot$ Anger $\cdot$ Stress $\cdot$ Negative affect

\begin{abstract}
Khat (Catha edulis) is a widely used stimulating drug often consumed in daily routine in Yemen and East African countries. Chewing khat acutely elicits states of euphoria and feelings of well-being which later shift into emotional instability and low mood. Little is known about emotional regulation in habitual khat chewers. In this study, we compared self-reports on trait anger as well as positive and negative affect responses to a mental arithmetic challenge. Participants included 135 men and women from Yemen who chew khat regularly, occasionally or not at all. Participants attended a laboratory session that involved resting periods and performing a math challenge. Analyses of variance and regression show that regular khat chewing is associated with higher trait anger, more pronounced negative responses during stress and less pronounced positive emotional states. These results suggest that regular khat chewing is associated with disturbances in emotion regulation processes.
\end{abstract}

Copyright $\odot 2011$ S. Karger AG, Basel
๑) 2011 S. Karger AG, Basel

Fax +41613061234 E-Mail karger@karger.ch www.karger.com

\section{Introduction}

Khat (Catha edulis) is an evergreen shrub that grows in areas bordering the Red Sea, including countries in East Africa and the Arabic Peninsula [1]. Its leaves are harvested and consumed legally in these regions. Usually the consumption is closely affiliated with social settings and traditions, particularly in Yemen where mostly male consumers come together in the afternoon to chew khat for several hours [2]. It is also consumed during work and by women, though less prominently.

The pharmacological effects of khat can be attributed to two phenylalkylamines - cathinone and cathine which are structurally related to amphetamines [3]. Cathinone is the more active ingredient of khat and has similar but milder effects than amphetamines. It induces an increase in the activity of the dopaminergic pathways in the central nervous system [4] and an inhibition of noradrenalin uptake [5]. The effects of cathine are less potent and do not last as long as those of cathinone. The effects of cathinone and cathine are similar in nature, though not in intensity, to those seen from amphetamines [6-8]. Consistent with these observations, khat chewing

Mustafa al'Absi, $\mathrm{PhD}$

Khat Research Program (KRP), University of Minnesota School of Medicine

1035 University Drive

Duluth, MN 55812 (USA)

Tel. +1 218726 7144, E-Mail malabsi@umn.edu 
sessions are initially characterized by positive feelings of optimism, alertness, and a general sense of euphoria and well-being $[1,9]$. After about $2 \mathrm{~h}$, however, chewers start reporting higher tension, irritation, sluggishness and a general low mood $[1,2]$. This negative tone usually lasts for several hours. However, the described dynamics vary between individuals and also depend on the type of khat that is chewed $[4,10]$.

Although these extensive observations have been discussed in connection with the effects of khat chewing on acute mood states, little systematic research has addressed mood and emotion regulation among habitual khat chewers. For example, work assessing emotional or mood states in a standardized way are virtually missing, with a few exceptions. Nencini et al. [11] used questionnaires and visual analog scales for mood assessments during a khat chewing session of habitual consumers. Their results indicated that euphoria, improved subjective intellectual efficiency and alertness were associated with khat consumption in 10 of 14 participants, but 4 participants experienced only dysphoria and mild sedation during the session as did all participants in the postchewing period. More recently, Gelaye et al. [12] investigated risk factors for violent behavior among male college students in Ethiopia and found that students who were regular khat chewers had a 1.45 odds ratio for violent behavior compared to those who did not chew khat. These observations suggest that khat chewers were less efficient in regulating negative emotional experiences.

Emotion regulation mechanisms, however, come particularly into play when individuals are confronted with stressful situations. For example, in relation to nicotine, an often used substance, we were able to demonstrate that hyporesponsiveness to mental and social stress predicted shorter time to relapse [13]. Further, high trait anger was associated with greater increases in state anger, withdrawal symptoms and craving during the first $24 \mathrm{~h}$ of abstinence from nicotine. High trait anger was also associated with increased risk for early relapse [14]. Smokers high in trait anger have greater mood difficulties during abstinence and are more vulnerable to early relapse than smokers with low trait anger. Research with other stimulant users suggests a role for anger, aggression and other emotion regulation factors in cocaine and amphetamine consumers [15-17]. These findings implicate trait anger to be associated with poor emotional regulation and vulnerability to substance misuse and relapse.

The objectives of the current study were to investigate possible differences in trait anger and anger coping behavior in khat chewers and to examine the extent to which habitual khat chewing is associated with altered mood states during mental stress. We expected that regular khat users report greater trait anger, and will report more negative and less positive affect during a lab stressor compared to those who do not use khat.

\section{Method}

Sample

Participants included 54 women and 81 men who were recruited to this cross-sectional study using flyers posted on campus and in the surrounding community at Sana'a University, Yemen. They had to be healthy and not on any prescribed medications to be enrolled in the study. Further, participants had to have at least a high school education level in order to ensure their ability to accomplish the tasks in this study. The age of the participants ranged from 16 to 41 years (mean $=24 ; \mathrm{SD}=5.5)$ and their BMI ranged from 14.42 to 40.89 (mean $=21.07$; $\mathrm{SD}=4.25)$, with about $26 \%$ having BMI $<18$ and about $4 \%$ having BMI $>30$. Participants signed a consent form approved by the research ethical committee at Sana'a University.

\section{Measures}

Trait Measures. An Arabic translated version of the Trait Anger Scale [18] was used. The translation was reviewed by an expert in the field, and the revision of the translation was conducted by local bilingual (Arabic-English) speakers. The scale contains 10 items and was administered during a screening session prior to a lab session. This Arabic version of the scale provides good internal consistency with Cronbach's $\alpha=0.82$.

Mood Measures. To measure the mood states during the lab session, we used a scale that obtains items to measure negative subjective states (irritable, tense, depressed, angry, impatient, confused) and positive subjective states (refreshed, content, calm, happy, in control, interested). On Likert scales raging from 0 (not at all) to 7 (a lot), participants rated their affective state. These items were taken from a similar measure that has been used widely in similar studies and in other countries [19-21]. The items were translated into Arabic language. Factor analyses conducted on data obtained during the baseline period in this sample yielded two factors corresponding to positive and negative subjective states according to the scree-plot and the eigenvalue $>1$ criteria. The two factors account for $58 \%$ of the variance. Analyses of reliability yielded internal consistencies (Cronbach's $\alpha$ ) of 0.82 and 0.86 for negative affect and positive affect, respectively. This mood measure was administered as a baseline measure before the stress period, again after the challenge and finally after a period of recovery from the challenge.

\section{Procedures}

Participants attended a screening session to insure eligibility for participation. After providing the consent form approved by the local ethical committee, they completed the trait questionnaire and provided information about their medical history and demographic information. Height and weight were also measured. Because we were interested in exploring the possibility of a dose-response relationship, participants were classified into one 
Table 1. Means \pm SD for age, BMI and trait anger for the three groups

\begin{tabular}{|c|c|c|c|c|c|c|}
\hline & \multicolumn{2}{|l|}{ Non-users } & \multicolumn{2}{|c|}{ Occasional users } & \multicolumn{2}{|l|}{ Regular users } \\
\hline & $\operatorname{men}(\mathrm{n}=21)$ & women $(\mathrm{n}=33)$ & men $(n=14)$ & women $(n=6)$ & $\operatorname{men}(n=42)$ & women $(n=11)$ \\
\hline Age, years & $24.00 \pm 4.84$ & $21.33 \pm 4.93$ & $25.57 \pm 8.32$ & $23.67 \pm 2.25$ & $24.21 \pm 5.14$ & $28.55 \pm 6.33$ \\
\hline $\mathrm{BMI}, \mathrm{kg} / \mathrm{m}^{2}$ & $21.71 \pm 4.19$ & $19.91 \pm 3.74$ & $19.39 \pm 2.91$ & $23.01 \pm 3.66$ & $20.75 \pm 3.55$ & $24.98 \pm 6.76$ \\
\hline Trait anger & $20.95 \pm 5.83$ & $20.11 \pm 5.22$ & $21.25 \pm 4.84$ & $18.83 \pm 5.43$ & $23.37 \pm 5.95$ & $23.64 \pm 4.57$ \\
\hline
\end{tabular}

of three groups. Those who reported to chew on a daily basis were included in the group of regular khat chewers, those who reported to use khat at least once a week but not daily constituted the group of occasional khat chewers, and the non khat chewers included those who reported never chewing or not having chewed in the last 2 years. This classification follows common khat chewing patterns. Within the group of non khat chewers, $6 \%$ of the participants were smokers, which is substantially less $\left[\chi^{2}(2)=\right.$ $22.33 ; \mathrm{p}<0.001$ ] than in the groups of occasional and regular khat chewers where 45 and $43 \%$ were smokers, respectively.

Participants were then scheduled for a laboratory stress session. All sessions were conducted in the morning, between 9 a.m. and 12 p.m. The lab session consisted of 3 periods: baseline measure, stress period (mental arithmetic with continuous backward subtraction by 7 , starting at 4001 for $8 \mathrm{~min}$ ) and a recovery period which lasted for $30 \mathrm{~min}$. It is important to note that participants were not going through withdrawal since they were not asked to restrict their khat chewing. However, they were also not under acute khat effects because their last use of khat was assumed to happen a day before or earlier, and the half-life of cathinone is ap-

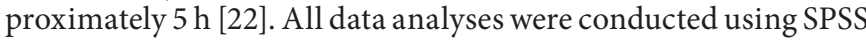
software packages.

\section{Results}

\section{Subject Characteristics}

Table 1 summarizes the demographic information (mean $\pm \mathrm{SD}$ ) for the three groups. Women were overrepresented in the group of non-users (61\%) and they were underrepresented in the groups of occasional and regular users (30 and 28\%, respectively). A three (khat groups) by two (sexes) ANOVA revealed a significant group by sex interaction on age $[\mathrm{F}(2,127)=4.46 ; \mathrm{p}=0.014]$, indicating that within the female population the regular khat chewers were older than the non-users, while no age differences were found among the male groups.

For BMI, ANOVA also revealed a group by sex interaction $[\mathrm{F}(2,127)=4.46 ; \mathrm{p}=0.014]$. As follow-up analyses showed, men and women did not differ in their BMI in the group of non-users, but within the groups of occasional and regular users, women had a greater BMI than men. Follow-up analyses also indicated that occasional and regular female khat chewers had greater BMI than female non-users, while the male groups did not differ in their BMI.

We found a main effect of khat chewing on trait anger $[\mathrm{F}(2,118)=5.12, \mathrm{p}<0.01] ;$ men and women who reported using khat regularly showed the highest trait anger values. They scored higher on trait anger than those who use khat occasionally $(\mathrm{p}=0.01)$ or never $(\mathrm{p}=0.06)$. There was no khat chewing by sex interaction (table 1 ).

\section{Baseline Affect Measures}

The three khat groups did not differ in negative affect during baseline $[F(2,121)=2.43 ; \mathrm{p}=0.78]$. Similarly there was no difference in negative affect between men and women and no group by sex interaction for negative affect ratings during baseline $(\mathrm{F}<0.3 ; \mathrm{p}>0.7)$. However, women reported less positive affect than men $[\mathrm{F}(1,121)=$ 4.16; $\mathrm{p}=0.04$ ] and khat chewing produced a significant main effect $[\mathrm{F}(2,121)=3.6 ; \mathrm{p}=0.03)$, though post-hoc tests did not reveal significant contrast effects between the three groups for positive affect during baseline. However, an inspection of the means in table 2 shows that the non khat chewers tended to score higher (mean $=3.72$; $\mathrm{SD}=1.55)$ than the occasional $($ mean $=3.18 ; \mathrm{SD}=1.30)$ and the regular users (mean $=3.20 ; \mathrm{SD}=1.23$ ).

\section{Effects of Stress on Negative and Positive Affect}

Two (sex: men and women) by three (khat chewing groups: no use, occasional use and regular use) by three (periods: baseline, stress and recovery) ANOVA revealed significant increases in negative affect during stress $[\mathrm{F}(2$, $240=11.92 ; \mathrm{p}<0.001]$. A group by period interaction was also significant $[\mathrm{F}(4,240=2.68 ; \mathrm{p}=0.03]$. This was due to an increase of negative affect in occasional and regular khat chewers, but not in non-users. There was no difference between men and women in negative affect throughout the session $[(\mathrm{F}(4,240)=1.72 ; \mathrm{p}=0.18$; table 2$]$. 
Table 2. Means \pm SD of positive and negative affect ratings of non-, occasional and regular users of khat during baseline, stress and recovery periods

\begin{tabular}{|c|c|c|c|c|c|c|}
\hline & \multicolumn{2}{|l|}{ Non-users } & \multicolumn{2}{|c|}{ Occasional users } & \multicolumn{2}{|c|}{ Regular users } \\
\hline & men & women & men & women & men & women \\
\hline \multicolumn{7}{|l|}{ Positive affect } \\
\hline Baseline & $4.14 \pm 1.84$ & $3.45 \pm 1.30$ & $3.42 \pm 1.22$ & $2.61 \pm 1.39$ & $3.27 \pm 1.32$ & $2.93 \pm 0.83$ \\
\hline Stress & $3.72 \pm 1.47$ & $3.12 \pm 1.43$ & $3.47 \pm 1.27$ & $1.75 \pm 0.65$ & $2.67 \pm 1.30$ & $2.25 \pm 0.53$ \\
\hline Recovery & $4.24 \pm 1.80$ & $3.39 \pm 1.55$ & $3.63 \pm 1.58$ & $2.06 \pm 1.22$ & $3.01 \pm 1.24$ & $2.34 \pm 1.16$ \\
\hline \multicolumn{7}{|l|}{ Negative affect } \\
\hline Baseline & $0.87 \pm 0.67$ & $1.04 \pm 1.04$ & $1.07 \pm 0.76$ & $1.22 \pm 0.81$ & $1.14 \pm 0.96$ & $1.00 \pm 0.91$ \\
\hline Stress & $0.94 \pm 0.67$ & $1.21 \pm 0.66$ & $1.20 \pm 1.04$ & $1.99 \pm 1.07$ & $1.86 \pm 1.45$ & $1.72 \pm 1.69$ \\
\hline Recovery & $0.82 \pm 0.69$ & $1.00 \pm 0.88$ & $1.20 \pm 1.08$ & $1.06 \pm 0.79$ & $1.43 \pm 1.15$ & $1.33 \pm 0.80$ \\
\hline
\end{tabular}

Table 3. Results of the regression analyses on peak negative and positive affect during the stress period

\begin{tabular}{lrrrl}
\hline $\begin{array}{l}\text { Dependent variable/ } \\
\text { independent variable }\end{array}$ & $\beta$ & $\mathrm{R}^{2}$ & $\begin{array}{c}\mathrm{T} / \\
\mathrm{F}(6,114)\end{array}$ \\
\hline Negative affect & & & & \\
$\quad$ Entire model & & 0.28 & 7.28 & 0.001 \\
Sex $^{\mathrm{a}}$ & -0.121 & & -1.36 & 0.17 \\
Age & -0.110 & -1.31 & 0.19 \\
BMI & -0.003 & -0.33 & 0.97 \\
Trait anger & 0.145 & 1.17 & 0.25 \\
Khat chewing & -0.448 & -1.36 & 0.18 \\
Trait anger by khat chewing & 0.829 & & 2.32 & 0.02 \\
Positive affect & & & \\
Entire model & & 0.18 & 4.09 & 0.001 \\
Sex & & & \\
Age & 0.218 & & 1.69 & 0.09 \\
BMI & 0.174 & & 1.87 & 0.06 \\
Trait anger & 0.116 & & 1.25 & 0.21 \\
Khat chewing & -0.016 & & -0.18 & 0.86 \\
Sex by khat chewing & 0.448 & -1.75 & 0.08 \\
\hline
\end{tabular}

a Sex: 1 = female; 2 = male.

${ }^{\mathrm{b}}$ Khat chewing: 1 = no; 2 = occasionally; 3 = regularly.

Similar analysis on positive affect showed that men reported more positive affect than women $[\mathrm{F}(1,120)=$ 9.53; $\mathrm{p}=0.003$ ]. Regular khat chewers reported less positive affect than occasional users and non-users $[\mathrm{F}(2,120)=6.80 ; \mathrm{p}=0.02] ;$ additionally, a significant decrease in positive affect during stress was found $[\mathrm{F}(2,240)=8.76 ; \mathrm{p}<0.001]$. These changes were similar in all groups $(\mathrm{F}<1.8 ; \mathrm{p}>0.17$; table 2$)$.

\section{Prediction of Affect during Baseline and Stress}

Regression analyses with negative affect and positive affect during baseline as outcome variables and sex ( $1=$ female, $2=$ male), age, BMI, trait anger and khat chewing as predictors showed that negative affect during baseline was not predicted by this model $[\mathrm{F}(5,116)=1.92 ; \mathrm{p}=0.1$; $\left.\mathrm{R}^{2}=0.08\right]$. For positive affect, the model revealed sex $(\beta=0.22 ; p=0.03)$ and khat-use status $(\beta=-0.31 ; p=$ $0.003)$ as significant predictor variables [entire model: $\left.\mathrm{F}(5,116)=2.3 ; \mathrm{p}=0.049 ; \mathrm{R}^{2}=0.09\right]$. Age, sex and BMI were added to the regression model because the groups differed with respect to these variables.

We also conducted multiple regression analyses to examine the extent to which trait anger and khat chewing status predicted peak negative affect during the stress period. The model also included sex, age and $\mathrm{BMI}$ as predictors. It was significant $\left[\mathrm{F}(5,115)=7.38 ; \mathrm{p}<0.001 ; \mathrm{R}^{2}=\right.$ $0.24]$ and trait anger $(\beta=0.36 ; \mathrm{p}<0.001)$ and khat chewing status $(\beta=0.28 ; p=0.003)$ were significant predictors within the model. Since the previously reported ANOVA has shown that trait anger depends on khat chewing status, in a subsequent step we added the interaction term of trait anger by khat chewing status to the model (table 3 ).

In this case only the interaction term was a significant predictor $(\beta=0.83 ; p=0.02)$. As shown in figure 1 , trait anger predicted negative affect report during stress only in the regular khat chewers.

A similar model was applied to positive affect during the stress period. In this case the model was significant $\left[\mathrm{F}(5,115)=4.96 ; \mathrm{p}<0.001 ; \mathrm{R}^{2}=0.18\right]$. Within the model, $\operatorname{sex}(\beta=0.27 ; p=0.005)$ and khat chewing status $(\beta=$ $-0.44 ; \mathrm{p}<0.001)$ were significant predictors. Adding the interaction term sex by khat chewing status to this did not affect the findings substantially. 

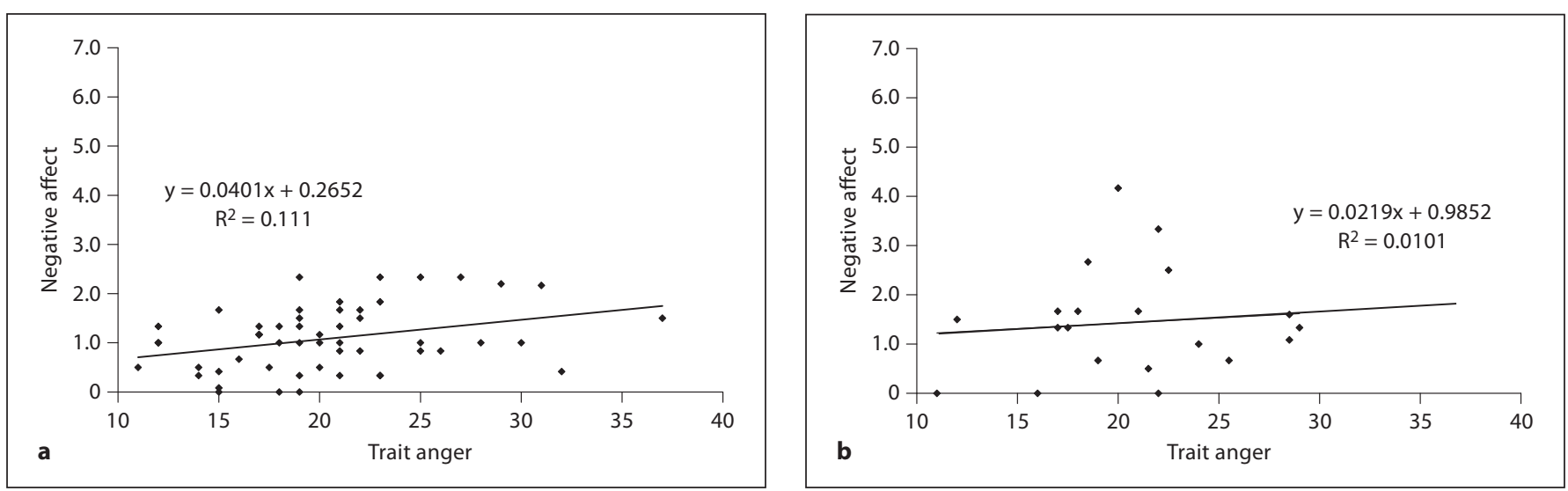

Fig. 1. Regression slopes for predicting peak negative affect during the stress period states by trait anger for the three groups of khat chewers: non khat users (a), occasional khat users (b) and regular khat users (c).

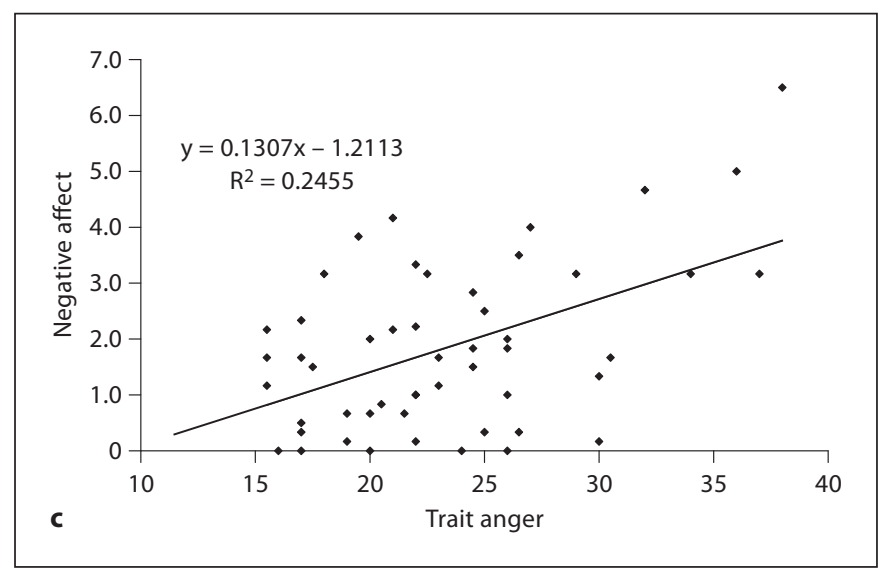

\section{Discussion}

This study shows that individual differences in trait anger and habitual khat chewing interact in their effect on the experiences of positive and negative emotional states. Regular khat chewing was associated with higher trait anger, more pronounced negative emotional responses during mental stress challenge and less pronounced positive emotional states at all times.

Khat chewers exhibited enhanced responses to acute stress as demonstrated by increased negative affect and reduced positive affect during the stressor. This enhanced emotional reactivity may represent a dispositional factor associated with risk for khat chewing, impact of chronic khat chewing on emotional regulation during acute stress, or delayed effects produced by the previous khat use episode. The fact that this enhanced sensitivity was also found in occasional users does not support the possibility of the acute effect hypothesis, keeping the other two possibilities as viable explanations. Indeed, the finding that trait anger predicted negative and positive affect

during the stressor supports this line of thinking, suggesting that khat-related emotional disposition (i.e. high level of trait anger) may predispose these individuals to experience enhanced negative affect during acute stressful situations.

Regular khat chewers scored higher on trait anger than occasional or non khat chewers. From our data we cannot conclude on any causal relationship between these two variables. It might be that the regular use of khat affects a person's personality in a way that he or she becomes more prone to experience anger. Observational data suggest that khat chewers experience a negative emotional state about $2 \mathrm{~h}$ after onset of a khat chewing session and that this state usually lasts for several hours $[1,9]$. Thus, it is possible that regular khat chewers tend to experience more negative emotions between khatchewing episodes and that the more frequently the khat chewing, the greater likelihood of experiencing these negative emotional states.

Another plausible interpretation is that dispositional anger-prone individuals may use khat as an instrument 
to regulate their negative mood. Indeed, research with nicotine dependence and other drug-using populations has shown high levels of depression, anxiety, history of trauma and other negative affect traits among these groups [19, 23-25], with evidence suggesting that dysphoric mood may play a role as a significant motivating factor for drug use [26-28] and may influence effects of stress [25]. Odenwald et al. [29] showed that traumatized combatants in Somalia show more extensive khat consumption than other Somalis, and they suggest that those individuals might use khat functionally in order to cope with their traumas. Finally, of course we cannot rule out that both khat chewing and trait anger are caused by a common third variable yet to be identified (e.g. sleep deprivation).

Khat chewers often smoke, and the effects of khat chewing might be confounded with those of smoking. In accordance with this, in our sample the nonsmokers were overrepresented in the group of non-chewers. However, the groups of occasional and regular khat chewers did not differ in their smoker/nonsmoker ratio, suggesting that the association found between trait anger and khat chewing cannot be explained by confounding smoking effects.

We note that this study was limited by the relatively small sample size, the self- and study selection criteria, and the unbalanced distribution of women across the groups. These limitations may limit the generalizability of the results. Future studies should address these limitations, attempt to carefully assess the role of sleep disturbances caused by khat use and systematically assess the effect of concurrent use of khat and other substances, such as tobacco and alcohol, with larger samples and longitudinal designs.
Nevertheless, this study is able to demonstrate that regular khat chewers show pronounced increases in negative affect during mental stress compared to occasional and non khat chewers. Further, while occasional and non-users showed negative affect ratings similar or below baselines and positive affect ratings similar to or above baselines after the recovery period, regular khat chewers reported consistently high negative affect and low positive affect throughout the session. These findings suggest a diminished capacity for emotion regulation in habitual khat chewers. It should be noted that the stress tests took place in the morning, i.e. at a time of the day when people usually abstain from khat. Thus, the findings may not be influenced by acute khat consumption.

In summary, this study shows that regular khat chewing is associated with increased predisposition to experience anger, and that khat chewers may exhibit enhanced emotional reactivity to stress. The current results suggest that habitual khat consumers share multiple common characteristics and mood profiles to those found among other psychostimulant users. Research into the extent to which khat effects on these emotional states may predispose chronic khat chewers to subsequent psychopathology is warranted.

\section{Acknowledgements}

This research was supported by a FIRCA grant from the National Institutes of Health/Fogarty International Center (R03TW007219), an R21 National Institute for Drug Abuse grant (DA024626) and a grant from the Office of International Programs at the University of Minnesota (PI: al'Absi).

\section{References}

1 Al-Hebshi NN, Skaug N: Khat (Catha edulis) - an updated review. Addict Biol 2005;10: 299-307.

2 Kennedy JG: The Flower of Paradise: The Institutionalized Use of the Drug Qat in North Yemen. Dordrecht, D. Reidel, 1987.

3 Kalix P: Khat, an amphetamine-like stimulant. J Psychoactive Drugs 1994;26:69-74.

4 Kalix P, Braenden O: Pharmacological aspects of the chewing of khat leaves. Pharmacol Rev 1985;37:149-164.

5 Drake HP: Khat-chewing in the Near East. Lancet 1988;331:532-533.

6 Hoffman R, al'Absi M: Khat use and neurobehavioral functions: suggestions for future studies. J Ethnopharmacol 2010;132: 554-563.
7 Hart JB, Wallace J: The adverse effects of am- 12 Gelaye B, Philpart M, Goshu M, Berhane Y, phetamine. Clin Toxicol 1975;8:179-190.

-8 Basunaid Y, Van Dongen M, Cleophas TJ: Khat abuse in Yemen: a population-based survey. Clin Res Regul Affairs 2008;25:87-92.

-9 Cox G, Rampes H: Adverse effects of khat: a review. Adv Psychiatr Treat 2003;9:456-463.

10 Al-Motarreb A, Baker K, Broadley KJ: Khat: pharmacological and medical aspects and its social use in Yemen. Phytother Res 2002;16: 403-413.

-11 Nencini P, Ahmed AM, Elmi AS: Subjective effects of khat chewing in humans. Drug Alcohol Depend 1986;18:97-105. Fitzpatrick AL, Williams MA: Anger expression, negative life events and violent behavior among male college students in Ethiopia. Scand J Public Health 2008;36:538-545.

13 al'Absi M: Hypothalamic-pituitary-adrenocortical responses to psychological stress and risk for smoking relapse. Int J Psychophysiol 2006;59:218-227.

14 al'Absi M, Carr S, Bongard S: Trait anger and psychobiological changes during smoking abstinence and in response to acute stress: prediction of smoking relapses. Int J Psychophysiol 2007;66:109-115. 
-15 Fox HC, Hong KI, Siedlarz K, Sinha R: Enhanced sensitivity to stress and drug/alcohol craving in abstinent cocaine-dependent individuals compared to social drinkers. Neuropsychopharmacology 2008;33:796-805.

-16 Goldstein RZ, Alia-Klein N, Leskovjan AC, Fowler JS, Wang GJ, Gur RC, Hitzemann R, Volkow ND: Anger and depression in cocaine addiction: association with the orbitofrontal cortex. Psychiatry Res 2005;138:1322.

-17 Stuart GL, Temple JR, Follansbee KW, Bucossi MM, Hellmuth JC, Moore TM: The role of drug use in a conceptual model of intimate partner violence in men and women arrested for domestic violence. Psychol Addict Behav 2008;22:12-24.

18 Spielberger CD: State-Trait Anger Expression Inventory. Odessa, Psychological Assessment Resources, 1988.

19 al'Absi M, Wittmers LE, Erickson J, Hatsukami D, Crouse B: Attenuated adrenocortical and blood pressure responses to psychological stress in ad libitum and abstinent smokers. Pharmacol Biochem Behav 2003; 74:401-410
20 Lovallo WR, Pincomb GA, Brackett DJ, Wilson MF: Heart rate reactivity as a predictor of neuroendocrine responses to aversive and appetitive challenges. Psychosom Med 1990; 52:17-26.

21 Lundberg U: Catecholamine and cortisol excretion under psychologically different laboratory conditions; in Usdin E, Kvetnanski R, Kopin I (eds): Catecholamines and Stress: Recent Advances. Amsterdam, Elsevier 1980.

22 Toennes SW, Harder S, Schramm M, Niess C, Kauert GF: Pharmacokinetics of cathinone, cathine and norephedrine after the chewing of khat leaves. Br J Clin Pharmacol 2003;56:125-130.

$\checkmark 23$ Anda RF, Williamson DF, Escobedo LG, Remington PL: Smoking and the risk of peptic ulcer disease among women in the United States. Arch Intern Med 1990;150:14371441.

24 Breslau N, Kilbe M, Andreski P: Nicotine dependence, major depression, and anxiety in young adults. Arch Gen Psychiatry 1991;48: 1069-1074.
25 Schäfer I, Teske L, Schulze-Thüsing J, Homann K, Reimer J, Haasen C, Hissbach J, Wiedemann K: Impact of childhood trauma on hypothalamus-pituitary-adrenal axis activity in alcohol-dependent patients. Eur Addict Res 2010;16:108-114.

26 Breslau N, Kilbey M, Andreski P: Nicotine withdrawal symptoms and psychiatric disorders: findings from an epidemiologic study of young adults. Am J Psychiatry 1992;149: 464-469.

27 Hall SM, Munoz R, Reus V: Smoking cessation, depression and dysphoria. NIDA Res Monogr 1991;105:312-313.

$>28$ Kendler KS, Neale MC, MacLean CJ, Heath AC, Eaves LJ, Kessler RC: Smoking and major depression: a causal analysis. Arch Gen Psychiatry 1993;50:36-43.

29 Odenwald M, Hinkel H, Schauer E, Schauer M, Elbert T, Neuner F, Rockstroh B: Use of khat and posttraumatic stress disorder as risk factors for psychotic symptoms: a study of Somali combatants. Soc Sci Med 2009;68: 1040-1048. 